\title{
El ambiente laboral de la cirugía: un esfuerzo de todos
}

\author{
The labor climate in surgery: an overall effort
}

\author{
Alejandro Múnera-Duque \\ Cirujano general; secretario, Asociación Colombiana de Cirugía; asociado, Cirujanos de Colombia, Sindicato de Gremio, \\ Medellín, Colombia
}

La vida laboral del especialista en Cirugía General y subespecialidades afines, tiene muchos interrogantes que no son discutidos en las universidades durante la formación. En el ejercicio de la profesión, las sociedades científicas que tienen el mayor número de asociados se quedan cortas cuando abordan estos temas porque carecen de interés académico y su objeto social no lo permite. Los sindicatos de gremio que están llamados a liderar estas discusiones, no logran reunir el número suficiente de especialistas para enfrentar los temas laborales y hacer evidente el problema del empleo médico en cirugía. Algunos de nuestros colegas están enfocados en obtener ingresos económicos y demuestran poco interés en hacer parte de esta discusión y, solo cuando ven en riesgo su estabilidad laboral, buscan en la asociación posibles soluciones para hacer de la nuestra una especialidad con ingresos y condiciones laborales acordes con la formación académica.

Los gerentes y los asesores jurídicos de las EPS y de las IPS tienen un conocimiento claro de los contratos laborales, las condiciones del mercado y la necesidad vanidosa del especialista de ser reconocido, lo que les da ventaja al momento de contratar nuestros servicios.

El desconocimiento y la desinformación relacionada con los aspectos laborales, llevan a algunos cirujanos a aceptar contratos desfavorables, bien sea por necesidad o seducidos por ofertas económicas que más adelante son incumplidas por los empleadores. No se dan cuenta de que, en algunos casos, ocultan la disminución de tarifas en salarios integrales sin aportes de seguridad social, y la pérdida de las prestaciones sociales y del derecho a los descansos, de los espacios de formación y actualización académica y de los tiempos protegidos de docencia que deberían ser remunerados, lo cual termina por menoscabar el gremio.

Motivados por nuestro presidente y la junta directiva de la Asociación Colombiana de Cirugía, presentaremos a los cirujanos del país artículos de carácter informativo, reflexivo y jurídico, elaborados por asociados, expertos en temas gremiales y abogados. Esperamos que estos aporten al conocimiento del mercado laboral de la cirugía y nos permita identificar los principales problemas del empleo médico, para tomar decisiones

Palabras clave: cirugía general; empleo; salarios y beneficios; satisfacción en el trabajo; legislación laboral.

Key words: general surgery; employment; salaries and fringe benefits; job satisfaction; legislation, labor.

Fecha de recibido: 26/12/2018 - Fecha aceptación: 28/12/2018

Correspondencia: Alejandro Múnera-Duque, MD

Correo electrónico: alejandromunerad@hotmail.com

Citar como: Múnera-Duque A. El ambiente laboral de la cirugía: un esfuerzo de todos. Rev Colomb Cir. 2019;34:14-5. https://doi.org/10.30944/20117582.92

Este es un artículo de acceso abierto bajo una Licencia Creative Commons - BY-NC-ND https://creativecommons.org/licenses/by-nc-nd/4.0/deed.es 
más informadas y asesoradas al momento de los procesos de contratación, ejecución y resolución de conflictos laborales, manteniendo unos lineamientos éticos y morales que nos lleven a competir y contratar con honorabilidad y calidad.

En vista de los múltiples conflictos laborales que ocurren a diario en nuestro país, que involucran colegas y asociados, nos corresponde como Asociación Colombiana de Cirugía usar el método científico y todas las herramientas académicas disponibles para entender la 'fisiopatología' de los aspectos laborales del sistema de salud colombiano y descifrarlo a fondo en busca de las causas que han deteriorado la ética y la moral de nuestra profesión. Esta es una profesión, en esencia, humana, que busca el bien para los demás, pero que extrañamente se comporta en sí misma como una enfermedad 'autoinmunitaria', que lleva a atacarnos entre nosotros mismos, sin medir las consecuencias y sin entender que cada acción que busque solo el beneficio individual, deteriora gravemente el ambiente laboral de todos los cirujanos y terminará afectándonos más adelante.

En un sistema de salud creado sin regulación laboral, que favorece los grandes grupos económicos y que ha deteriorado gravemente la condición laboral y salarial del cirujano, las asociaciones y gremios nos vemos en la necesidad de convocar a la unidad de los cirujanos generales y subespecialistas para que, agremiados en una sociedad o en un sindicato madre, busquemos reivindicar el derecho al trabajo digno en hospitales y clínicas que cuenten con los recursos ne- cesarios para ejercer una medicina de calidad, sin barreras administrativas que pongan en riesgo la vida de nuestros pacientes, la integridad física, moral y patrimonial del cirujano, el derecho a la seguridad y las prestaciones sociales de ley, una remuneración acorde con la profesión.

La asociación no cuenta con mecanismos de presión económica ni jurídica para regular el mercado de la cirugía en Colombia y, aunque existe la sanción ética y social como herramienta disponible, desde la asociación creemos que no debería ser usada en personas con tan alto nivel de formación científico y humano. Por eso, apelamos a los códigos de buena conducta y a la formación moral obtenida por cada uno de nosotros, para que respetemos los puestos de trabajo de nuestros colegas, cuidemos nuestros puestos de trabajo convirtiéndonos en aliados de las instituciones donde trabajamos. Además, para que, unidos en la misma asociación, creemos estrategias para impulsar proyectos de ley que intervengan activamente en: la certificación y recertificación (licencias); las tarifas mínimas de horas y procedimientos; el registro de nuevos procedimientos en la CUPS (Clasificación Única de Procedimientos en Salud) y la actualización de los existentes con valores acordes con la complejidad; nuevas alternativas de ingresos económicos, como programas de educación continua, asesorías, cursos y talleres; y un manual de ejercicio y comportamiento que nos permita nuevamente autorregular el mercado de la cirugía en Colombia para beneficiar a los pacientes y a nuestra profesión. 